\title{
Analysis of Prescribing Pattern, Efficacy and Adverse Drug Reactions of Anti-diabetic Agents in Type-2 Diabetic Patients at a Tertiary Care Teaching Hospital
}

\author{
Avneesh Kumar ${ }^{1 *}$, Asha Pathak', Alok Dixit ${ }^{1}$ and Manoj Kumar ${ }^{2}$ \\ 'Department of Pharmacology, Uttar Pradesh University of Medical Sciences Saifai, \\ Etawah - 206130, Uttar Pradesh, India; dravneesh16@gmail.com \\ ${ }^{2}$ Department of Medicine, Uttar Pradesh University of Medical Sciences Saifai, \\ Etawah - 206130, Uttar Pradesh, India
}

\begin{abstract}
Prescription pattern analysis provides guidance to utilize available drugs rationally. Diabetes is a chronic, hyperglycaemic metabolic disorder with subsequent complications. The aim of present study is to analyse prescribing pattern, efficacy and Adverse Drug Reactions (ADRs) of Anti-diabetic Drugs (ADDs) in our tertiary care teaching institute. A prospective analytical study was conducted and demographical details, investigations (fasting, postprandial blood glucose and HbA1C at every 3 months, LFT, Lipid profile and KFT) and prescriptions were collected from 135 uncomplicated Type-2 diabetic patients visiting Medicine OPD over a period of 18 months. Prescriptions were collected and ADDs, fixed dose combinations (FDCs), other medicines used and ADRs were also recorded. Data collected was analysed using t-test and chi-square test. 94 (69.63\%) patients were of 41-60 years age group with mean BMI of $26.63 \pm 3.26$. Fasting, postprandial blood glucose and HbA1c initially and at 18 months were $193 \pm 65,284 \pm 78,9.2 \pm 2.3$ and $107 \pm 15,163 \pm 23,6.5 \pm 0.6$ respectively with a significant reduction in mean fasting, postprandial blood glucose and HBA1c at 18 months $(\mathrm{P}<0.0001)$. Total drugs prescribed were 331, ADDs 222 (67.07\%), FDCs 61 (18.43\%), generic drugs 270 (81.57\%), drugs from National list of Essential Medicines 259 (78.25\%), injectables 2 (1.48\%), other group of drugs 48 (14.50\%) and ADRs 21 (15.56\%). Average drugs per prescription were 2.45 and ADDs 1.64. The present study showed that the prescriptions were rational, drugs used were efficacious and ADRs mild and transient.
\end{abstract}

Keywords: Antidiabetic Drugs, NLEM, Prescribing Pattern

\section{Introduction}

Diabetes (DM), affects large section of Indian population and is rapidly becoming a diabetes capital of world. According to Diabetes Atlas (DA) a document of International Diabetes Federation (IDF), it is estimated about India that there will be an increase in number of cases to about 70 million by 2025 and it is estimated that every fifth person will be suffering from diabetes in India. A similar rise is estimated worldwide where it is expected to escalate to about 366 million by $2030^{1}$. Diabetes Mellitus is an aggregate of metabolic disorders that presents as 
hyperglycaemia as a result of imbalance in carbohydrates and fat biotransformation that ultimately results in micro as well as macrovascular complexities ${ }^{2}$.

Prescription pattern analysis provides guidance about existing drug utilization and to implement measures for rational utilization of available drugs ${ }^{3}$. Studies analysing prescriptions also enable and provide guidance to use drugs for the right patient in correct dose for appropriate duration so as to provide maximum therapeutic benefit to the patient. Studies conducting prescription analysis for chronic disease like Diabetes Mellitus give us knowledge about prevalence of disease, ways to decrease morbidity and provide estimates about efficacy and toxicity of various drugs ${ }^{4}$. Such studies give appropriate knowledge regarding recent prescribing trends and to recognise whether prescription is rational or irrational. It is observed that irrational prescription of drugs often lead to non-adherence of antidiabetic drugs and thus making the disease more complex due to increase in blood sugar. This will further increase the expenditure on drugs and health needs ${ }^{5}$.

Studies evaluating drug utilization pattern for Diabetes Mellitus in past have shown metformin as the most prescribed drug followed by sulphonylureas ${ }^{6}$. A study evaluating adherence to ADD in Nepal has shown that metformin alone is most frequently prescribed, ${ }^{7}$ whereas use of metformin in fixed dose combinations was roughly $20 \%$ from a study in India, ${ }^{8}$ the use of metformin in combination with other medications has been reported to nearly $60 \%$ from a Taiwanese study 9 Such prescription audits for chronic disorders such as $\mathrm{DM}$ offer us clue for drug utilization and allow us to use corrective steps for rational use of drugs. Considering all these trends and utility of such studies, we planned a study to analyze the prescribing patterns of anti diabetic agents in Type-2 diabetic patients at our tertiary care teaching institute. The aim of our study was to analyse recent trends in prescription, efficacy and adverse effects if any of antidiabetic agents in Type- 2 diabetic patients.

\section{Material and Methods}

After prior approval from Institutional Ethics Committee (IEC No: 157/2018), a prospective observational study was conducted on patients attending outpatient department of Medicine in UPUMS, Saifai, (Etawah) with Type-2 diabetes over a period of 18 months. Sample constituted of patients attending Medicine OPD for first 6 months and was recruited over the time and subsequently followed up for next 12 months. Patients with age $\geq 18$ years of both gender and meeting the diagnostic criteria of Type- 2 Diabetes Mellitus were included in study while those with age less than 18 years, Type-1 diabetes/juvenile diabetes, gestational diabetes, patients admitted in hospital/with complications and patients with mental incompetence/ with psychiatric disorder were excluded.

A sample of patients fulfilling the inclusion criteria were recruited after obtaining informed consent from the patients and a complete medical history including social demographic profile was gathered and thorough examination (including general and systemic) was done. The patients were diagnosed as Type-2 diabetes in outpatient department of Medicine based on clinical criteria for diagnosis of diabetes ${ }^{4}$ (Table 1 ).

Prescriptions were collected by taking image of the prescription and recorded on predesigned case study proforma. Detailed information regarding sociodemographic data, anti-diabetic drugs used, and duration of treatment, Adverse Drug Reactions (ADR) and dietary/exercise activities was recorded. The body mass index (BMI), HbAlc, blood sugar (fasting, postprandial), lipid profile (serum cholesterol, serum triglycerides, HDL, LDL, VLDL), liver function tests (serum bilirubin, serum albumin, SGOT, SGPT, ALP) and kidney function tests (urea, creatinine) were estimated initially and at 18 months. Repeat fasting, postprandial blood sugar and $\mathrm{HbAlc}$ was estimated at every 3 months interval.

Table 1. Diagnostic criteria for Type-2 Diabetes Mellitus $^{4}$

Fasting plasma glucose $\geq 126 \mathrm{mg} / \mathrm{dl}(7.0 \mathrm{mmol} / \mathrm{L})$. Fasting defined as not taking any calorie for about $8 \mathrm{~h}$.

OR

2-h postprandial glucose $\geq 200 \mathrm{mg} / \mathrm{dl}(11.1 \mathrm{mmol} / \mathrm{L})$ during oral glucose tolerance test (OGTT). As per WHO guideline OGTT is performed by giving a glucose constituent equal to 75-g anhydrous glucose with water.

\section{OR}

Glycosylated haemoglobin (HbAlc) $\geq 6.5 \%$ (48 $\mathrm{mmol} / \mathrm{mol})$. Test for HbA1c should be as per NGSP certification and quality as per DCCT assay.

\section{OR}

Patient having typical symptoms of increased blood glucose or emergency due increased blood glucose, random plasma glucose $\geq 200 \mathrm{mg} / \mathrm{dl}(11.1 \mathrm{mmol} / \mathrm{L})$. 


\section{Statistical Analysis}

Study was completed on intention to treat principle. Continuous and categorical variables were evaluated using student $\mathrm{t}$-test and chi-square test respectively and conducted on statistical package for social sciences (SPSS version 24 ) and $\mathrm{P}$-value $<0.05$ was considered statistically significant.

\section{Results}

The present prospective analytical study was done at Medicine outpatient department, UPUMS, Saifai [Etawah, (U.P)] for a period of 1 year and 6 months (from February 2019 to July 2020). Total 135 Type-2 diabetic patients without complications completed the study and their data collected as per case proforma was analyzed for epidemiologic profile, drug prescription patterns, efficacy and adverse drug reactions. Demographic profile of patients is as shown in Table 2, with majority of patients in age group 41-60 years had male to female ratio of 0.96 .

Regular fasting, postprandial blood sugar and $\mathrm{HbAlc}$ were estimated at every 3 months interval as shown in Tables 3, 4 and Figure 1 and significant reduction was observed in mean fasting, postprandial blood sugar and HBA1c at the end of 18 months $(\mathrm{P}<0.05)$. A significant decrease in number of patients who had unsatisfactory fasting and postprandial blood sugar control was also observed $(\mathrm{P}<0.001)$. Liver Function Tests, Lipid profile and Kidney Function tests of all 135 patients were recorded at baseline and 18 months interval and were within normal limits.

\subsection{Analysis of Pattern for Number of Drugs Prescribed}

Total number of prescriptions analysed were 135. All the drugs prescribed to Type- 2 diabetic patients were regularly recorded at every 3 months interval. The drugs

Table 2. Demographic characteristic of Type-2 diabetic patient

\begin{tabular}{|c|c|c|}
\hline Age group (years) & Total (\%) & \multirow{4}{*}{$\begin{array}{c}\text { Age }(\text { mean } \text { SD }) \\
51.87 \pm 9.24 \text { years }\end{array}$} \\
\hline $21-40$ & $18(13.33 \%)$ & \\
\hline $41-60$ & $94(69.63 \%)$ & \\
\hline $61-80$ & $23(17.04 \%)$ & \\
\hline Sex & Total (\%) & \multirow{3}{*}{$\begin{array}{c}\text { Male : Female } \\
\text { Ratio } \\
0.96 \\
\end{array}$} \\
\hline Male & $66(48.89 \%)$ & \\
\hline Female & $69(51.11 \%)$ & \\
\hline Exercise & Number (\%) & \\
\hline Yes & $11(8.15 \%)$ & \\
\hline No & $110(81.48 \%)$ & \\
\hline Physiotherapy & $14(10.37 \%)$ & \\
\hline Family history of DM & Number (\%) & \\
\hline Yes & $46(34.07 \%)$ & \\
\hline No & $73(54.07 \%)$ & \\
\hline Not significant & $16(11.86 \%)$ & \\
\hline BMI range $\left(\mathrm{kg} / \mathrm{m}^{2}\right)$ & Total (\%) & \multirow{5}{*}{$\begin{array}{c}\text { BMI (mean SD) } \\
26.63 \pm 3.26 \mathrm{~kg} / \mathrm{m}^{2}\end{array}$} \\
\hline Minor (17-24) & $25(18.52 \%)$ & \\
\hline Moderate (25-27) & $54(40 \%)$ & \\
\hline High (28-40) & $56(41.48 \%)$ & \\
\hline Severe $(40-50)$ & - & \\
\hline
\end{tabular}

Table 3. Satisfactory and unsatisfactory fasting and postprandial blood glucose control in Type-2 Diabetic Patients

\begin{tabular}{|c|c|c|c|c|c|c|c|c|}
\hline & \multicolumn{4}{|c|}{ Fasting blood glucose control } & \multicolumn{4}{|c|}{ Postprandial blood glucose control } \\
\hline & \multicolumn{2}{|c|}{$\begin{array}{c}\text { Satisfactory control } \\
<126 \mathrm{mg} / \mathrm{dl}\end{array}$} & \multicolumn{2}{|c|}{$\begin{array}{c}\text { Unsatisfactory control } \\
\geq 126 \mathrm{mg} / \mathrm{dl} \\
\end{array}$} & \multicolumn{2}{|c|}{$\begin{array}{c}\text { Satisfactory control } \\
<200 \mathrm{mg} / \mathrm{dl}\end{array}$} & \multicolumn{2}{|c|}{$\begin{array}{l}\text { Unsatisfactory control } \\
\geq 200 \mathrm{mg} / \mathrm{dl}\end{array}$} \\
\hline & $\mathbf{N}$ & $\%$ & $\mathbf{N}$ & $\%$ & $\mathbf{N}$ & $\%$ & $\mathbf{N}$ & $\%$ \\
\hline Baseline & 20 & 14.81 & $115^{*}$ & 85.19 & 14 & 10.37 & $121^{*}$ & 89.63 \\
\hline 3months & 70 & 51.85 & 65 & 48.15 & 47 & 34.81 & 88 & 65.19 \\
\hline 6months & 97 & 71.85 & 38 & 28.15 & 78 & 57.78 & 57 & 42.22 \\
\hline 9months & 118 & 87.41 & 17 & 12.59 & 106 & 78.52 & 29 & 21.48 \\
\hline 12months & 41 & 30.37 & 3 & 2.22 & 40 & 29.63 & 5 & 3.70 \\
\hline 15months & 14 & 10.37 & 0 & 0.00 & 12 & 8.89 & 2 & 1.48 \\
\hline 18months & 126 & 93.33 & $9^{*}$ & 6.67 & 119 & 88.15 & $16^{*}$ & 11.85 \\
\hline
\end{tabular}


prescribed were ADDs, Injectables (Insulins), FDCs and other Drugs like NSAIDs, Supplements, Lipid lowering agents, Antimicrobials, Antacids and Anti-histaminics. An average of 2.45 drugs was prescribed per prescription. (Table 6).

Table 4. Range of HbAlc percentage of Type-2 diabetic patients

\begin{tabular}{|c|c|c|c|c|}
\hline \multirow{2}{*}{} & \multicolumn{4}{|c|}{ HbA1C (\%) } \\
\cline { 2 - 5 } & \multicolumn{2}{|c|}{$<6.5$} & \multicolumn{2}{c|}{$>6.5$} \\
\cline { 2 - 5 } & $\mathrm{N}$ & $\%$ & $\mathrm{~N}$ & $\%$ \\
\hline Base line & 2 & 1.48 & 133 & 98.52 \\
\hline 3 months & 12 & 8.89 & 123 & 91.11 \\
\hline 6 months & 27 & 20.00 & 106 & 78.51 \\
\hline 9 months & 42 & 31.11 & 93 & 68.89 \\
\hline 12 months & 21 & 15.56 & 23 & 17.04 \\
\hline 15 months & 3 & 2.22 & 11 & 8.15 \\
\hline 18 months & 56 & 41.48 & 79 & 58.52 \\
\hline
\end{tabular}

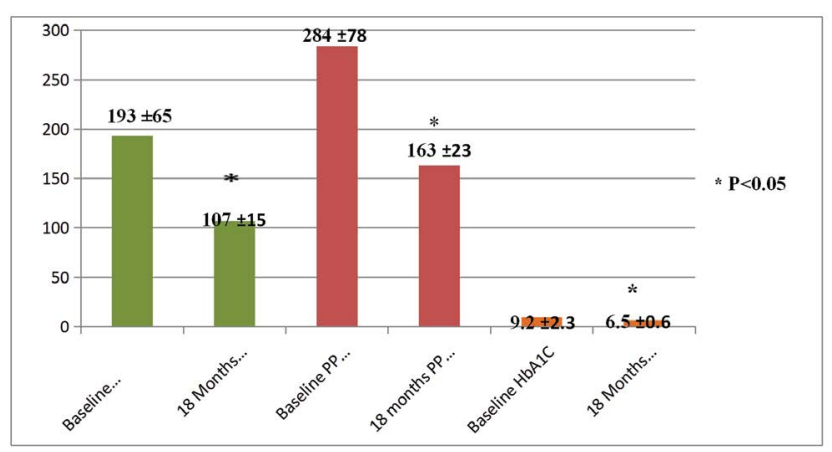

Figure 1. Comparision of fasting, postprandial blood glucose and $\mathrm{HbA1C}$ at baseline and 18 months.

\subsection{Analysis of Pattern for Anti-diabetic Drugs (ADDs) Prescribed}

ADDs prescribed were: Oral Hypoglycaemic drugs and Insulins in either monotherapy or combination therapy. Prescriptions were recorded regularly for ADDs at 3 months interval. Initially Oral Hypoglycaemic drugs were prescribed for 133 (98.52\%) prescriptions while Insulins were prescribed for $2(1.48 \%)$ prescriptions. Finally at $18^{\text {th }}$ months all 135 (100\%) prescriptions consisted of Oral Hypoglycaemic drugs that were prescribed only from 2 classes i.e. Biguanides (Metformin) and Sulphonylureas (Glimepride) either

Table 6. Analysis of prescribing indicators in Type-2 Diabetes Mellitus patients

\begin{tabular}{|l|c|}
\hline Number of prescriptions studied & 135 \\
\hline Prescription detail & $\begin{array}{c}\text { Total number } \\
\text { of drugs } \\
\text { prescribed (\%) }\end{array}$ \\
\hline Overall drugs prescribed & 331 \\
\hline Antidiabetic drugs & $222(67.07 \%)$ \\
\hline Mean drugs per prescription & 2.45 \\
\hline Mean antidiabetic drugs per prescription & 1.64 \\
\hline $\begin{array}{l}\text { Drugs from National list of essential } \\
\text { medicines (NLEM) }\end{array}$ & $259(78.25 \%)$ \\
\hline $\begin{array}{l}\text { Fixed drug combination (FDCs) } \\
\text { prescribed }\end{array}$ & $61(18.43 \%)$ \\
\hline Drugs prescribed by generic name & $270(81.57 \%)$ \\
\hline $\begin{array}{l}\text { Other drugs prescribed out of total drugs } \\
\text { prescribed }\end{array}$ & $48(14.50 \%)$ \\
\hline Injections prescribed & $2(1.48 \%)$ \\
\hline
\end{tabular}

Table 5. Total number of drugs prescribed to Type-2 diabetic patients

\begin{tabular}{|c|c|c|c|c|c|c|c|c|c|c|c|c|}
\hline & \multicolumn{12}{|c|}{ Drugs in total number prescribed } \\
\hline & \multicolumn{2}{|c|}{1} & \multicolumn{2}{|c|}{2} & \multicolumn{2}{|c|}{3} & \multicolumn{2}{|c|}{4} & \multicolumn{2}{|c|}{5} & \multicolumn{2}{|c|}{6} \\
\hline & $\mathrm{N}$ & $\%$ & $\mathrm{~N}$ & $\%$ & $\mathrm{~N}$ & $\%$ & $\mathrm{~N}$ & $\%$ & $\mathrm{~N}$ & $\%$ & $\mathrm{~N}$ & $\%$ \\
\hline Base line & 16 & 11.85 & 54 & 40.00 & 50 & 37.04 & 12 & 8.89 & & & 3 & 2.22 \\
\hline 3 months & 13 & 9.63 & 63 & 46.67 & 48 & 35.56 & 7 & 5.19 & 3 & 2.22 & 1 & 0.74 \\
\hline 6 months & 10 & 7.41 & 66 & 48.89 & 50 & 37.04 & 9 & 6.67 & & & & \\
\hline 9 months & 10 & 7.41 & 66 & 48.89 & 51 & 37.78 & 8 & 5.93 & & & & \\
\hline 12 months & 6 & 4.44 & 19 & 14.07 & 18 & 13.33 & 2 & 1.48 & & & & \\
\hline 15 months & & 0.00 & 5 & 3.70 & 7 & 5.19 & 2 & 1.48 & & & & \\
\hline 18 months & 9 & 6.67 & 68 & 50.37 & 49 & 36.30 & 9 & 6.67 & & & & \\
\hline
\end{tabular}


in the form of mono or combination therapy and only in combination therapy respectively. Biguanides (Metformin) was most commonly prescribed class (ADD) to 133 (98.52\%) patients initially and to 135 (100\%) patients at 18 months both as mono and combination therapy. Sulphonylureas (Glimepride) was the next most prescribed class of ADDs to 109 (80.74\%) patients initially and to $117(86.67 \%)$ at 18 months, but only in combination with Metformin. Insulins were the least prescribed class to $2(1.48 \%)$ patients initially and to none at 18 months. Metformin was prescribed as Metformin-500 mg and Metformin-1000 mg 2-3 times daily as monotherapy and with Glimepride- $1 \mathrm{mg}$ and Glimepride-2 mg 2-3 times daily as combination therapy. Insulins was prescribed as monotherapy in the form of Short-acting Soluble/Regular Insulin as monotherapy and in combination as Mixtard Insulin $30 / 70$ consisting of $30 \%$ Short-acting Soluble/Regular Insulin $+70 \%$ Intermediate/Isophane Insulin.

\subsection{Monotherapy}

Out of total 135 Type- 2 diabetic patients, initially 24 (17.78\%) at 3 months $23(17.04 \%)$, at 6 and 9 months $18(13.33 \%)$, at 12 and 15 months as mentioned before due to Covid-19 pandemic only 8 (5.93\%) patients were recorded and at 18 months 18 (13.33\%) patients were on monotherapy of ADDS. Biguanides (Metformin) was most commonly prescribed anti-diabetic agent as $17.04 \%$ initially and $13.33 \%$ at $18^{\text {th }}$ month followed by Insulin (Short-acting Soluble/Regular Insulin in $1(0.74 \%)$ only initially. Initially and at 18 months Metformin-500 mg 3 times a day was most frequently prescribed drug.

\subsection{Combination Therapy}

Combination therapy of ADDs were all in the form of 2 drug therapy, included either a combination of Biguanide with Sulphonylureas in various combinations or a shortacting with Intermediate Insulin. ADDs were prescribed in combinations initially to 111 (82.22\%) patients, to 112 (82.96\%) patients at 3 months, to $117(86.67 \%)$ patients at 6 and 9 months, to $37(27.41 \%)$ patients at 12 months, to $14(10.37 \%)$ patients at 15 months and to 117 (86.67\%) patients at 18 months. Combination Metformin-1000 mg 2 times a day + Glimepride- $1 \mathrm{mg} 2$ times a day was the most common combination prescribed initially while Metformin-500 mg 3 times a day + Glimepride-1 mg 1 time a day was most common combination prescribed at 18 months.

\subsection{Fixed Drug Combinations (FDCs) and other Group of Drugs}

FDCs prescribed were 61 which constituted (18.43\%) of total number of drugs prescribed. Commonest FDCs prescribed were Pregaba $M$ to 58 (42.96\%) of total patients and Amoxyclav 625 prescribed to $3(2.22 \%)$ of total patients. 1 patient $(0.74 \%)$ was prescribed both the FDCs. Other group of drugs prescribed were: NSAIDs 3 (2.22\%), Supplements 12 (8.89\%), Lipid lowering agents 9 (6.67\%), Antimicrobials 6 (4.44\%), Antacids 14 (10.37\%) and Anti-histaminics 4 (2.96\%) of total number of prescriptions. Other group of drugs prescribed were 48 $(14.50 \%)$ of the overall drugs prescribed.

\subsection{Analysis of Prescribing Indicators}

All the drugs prescribed were from National list of Essential Medicine (NLEM) except Omeprazole prescribed in $14(4.23 \%)$ of total prescribed drugs and Pregaba-M (FDC) prescribed to $58(17.52 \%)$ of total drugs prescribed (Table 6).

Adverse drug reactions were reported in 21 patients, 7 (5.19\%) females and 14 males (10.37\%) and total number of ADRs reported were 27 (20\%) of total patient prescriptions. Most ADRs were reported in age group 41-60 years. The occurrence of ADRs was significantly associated with combination therapy as compared to monotherapy (Figure 2).

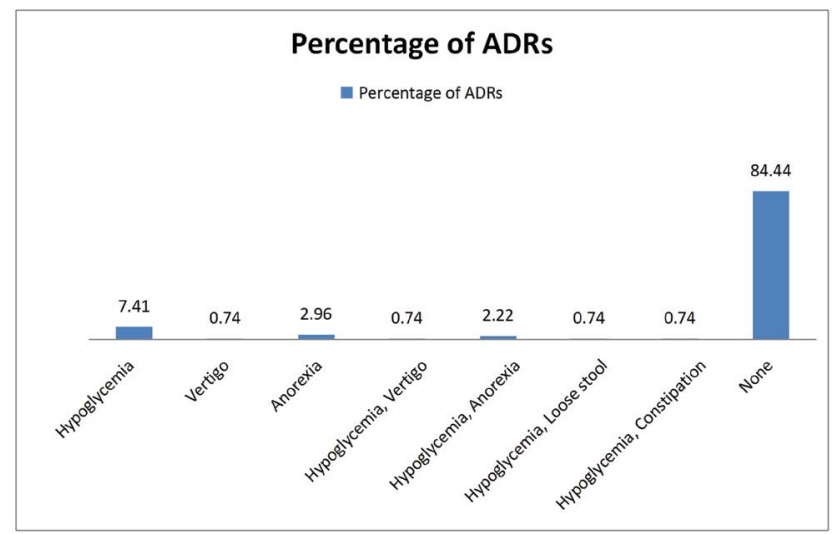

Figure 2. Analysis of ADR in Type-2 diabetic patients in percentage. 


\section{Discussion}

Majority 94 (69.63\%) patients were of age group 41-60 years. This has been very often observed as risk of Type- 2 Diabetes Mellitus increases with age. Our findings in the present study are consistent with previous studies that had majority of patients in 51-70 years age group ${ }^{6,10,11}$. 66 males (48.89\%) and 69 females (51.11\%) were enrolled in present study with a male:female ratio of 0.96 . However, men seem more susceptible to DM due to the consequences of obesity as prevalent in this part of country. Similar results were obtained in several studies from India ${ }^{6,11,12}$.

Prolonged counselling sessions were conducted for all patients. $11(8.15 \%)$ patients followed lifestyle modification while $14(10.37 \%)$ patients were receiving physiotherapy. For some, this may be enough to eliminate the need for medicine and there are studies that have shown encouraging results with initiation of therapy with lifestyle modifications, mixed vegetarian diet, physiotherapy and doing regular exercise ${ }^{13-15}$.

In the present study 46 (34.07\%) patients reported the occurrence of diabetes in the family of either of their parents. Epidemiological studies have shown that family history of diabetes has a correlation to reduced insulin sensitivity in progenies. Positive family history of DM in patients have been reported in several national as well as international studies as reflected in our study too ${ }^{6,12,15}$.

Body Mass Index of $>24$ was observed in 110 (81.48\%) patients with mean $\pm \mathrm{SD}$ as $26.63 \pm 3.26 \mathrm{~kg} / \mathrm{m}^{2}$. Studies have shown that Diabetes Mellitus is associated with raised BMI. Similar findings of increased BMI in patients of DM has been observed where $57 \%$ had BMI over $25^{15,16}$. Similarly, a Nepalese study has also reported a mean BMI of $23.83 \mathrm{~kg} / \mathrm{m}^{27}$.

In our study there was a significant reduction in mean fasting, postprandial blood glucose and HbAlc at 18 months $(\mathrm{P}<0.0001)$. Significant reduction in fasting, postprandial blood glucose and $\mathrm{HbAlc}$ in our study indicate rational and efficacious usage of drugs. Similar studies done in past reported that $41(41 \%)$ patients had controlled optimal glycaemic levels, ${ }^{8} 72.3 \%$ had controlled blood glucose levels posttherapy ${ }^{15}$ and majority patients had fasting and postprandial blood sugar levels in the range of $161-200 \mathrm{mg} / \mathrm{dl}^{10}$.

Study based on prescription analysis is regarded to be an efficacious way of making assessment and evaluation of trends in prescription of medicines. In the present study a total of 331 drugs were prescribed at an average of 2.45 drugs per prescription. Mean antidiabetic drugs per prescription was 1.64 drugs per prescription. Thus drugs prescribed in the present study based on evidence were rational. Similarly some studies conducted had almost similar findings with some variations due to variable number of patients as well as the availability and preference of the particular drug/drugs at those sites. ADDs prescribed in form of fixed dose combination may pose a problem related to dose adjustment on further follow-up and may be avoided as far as possible. Though these are very likely to improve compliance in the patient and therefore may be used once the dose adjustment in a particular patient has been achieved. Our findings correlate with the observation of previous studies where mean drugs per prescription was $2.03^{17}$, metformin alone was used in $49.7 \%{ }^{7}$, combination therapy was prescribed to $60 \%$ of all prescriptions ${ }^{9}$ and metformin was the commonly prescribed medicine and sulphonylureas were the second most commonly prescribed drug 6 .

There were almost no significant adverse effects on organ function tests during the course of study. Adverse drug reactions of ADDs were mild and transient in total 21 (15.56\%) of prescriptions and $27(20 \%)$ in total patients. Evaluation of ADRs is important for the assessment of risk factors to ensure maximum benefits of drug therapy, compliance and also confirms the rational usage of drugs. Our results for ADRs were quite satisfactory and encouraging as several other studies conducted on ADDs reported ADRs about $40 \%,{ }^{18,19}$ and nearly $30 \%^{7}$ and thus combination therapy was used in these study to prevent adverse reaction such as lactic acidosis caused due to metformin $^{20}$.

A major limitation in our study was use of only those drugs which were available in our hospital pharmacy and thus may bias the results. The study period also coincided with COVID pandemic resulting in lockdown and difficulty in patient follow-up as a result.

\section{Conclusion}

Oral hypoglycaemic agents still lead anti-diabetic agents in management of Type-2 DM and the antidiabetic agents used in our study were efficaceous. Biguanides (Metformin) was the most frequent drug prescribed amongst anti-diabetic drug class, followed by sulphonylureas (Glimepride). Metformin with glimepiride was the most frequently prescribed combination therapy 
and was associated with more adverse drug reactions followed by monotherapy with insulin. Hypoglycaemia was reported as the most frequent adverse drug reaction in our study. To conclude the present study shows that the prescriptions were rational, drugs prescribed were efficacious and ADRs mild and transient with the use of ADDs prescribed.

\section{References}

1. Sutharson L, Hariharan RS, Vamsadhara C. Drug utilization study in diabetology outpatient of a tertiary hospital. Indian J Pharmacol. 2003; 35:237-40.

2. DiPiro, J, Talbert, R, Yee G, Matzke G, Wells B, Posey L, Streetman D, Streetman D. Book Review: Pharmacotherapy: A Pathophysiologic Approach, $7^{\text {th }}$ Ed. Annals of Pharmacotherapy. 2009; 43(2):395-395. https://doi.org/10.1345/aph.1L477

3. Bhanu P, Prasanand S, Divyashanthi CM, Annabelle R, Pandiamunian J. Prescribing pattern and WHO core prescribing indicators in post-operative patients of gynaecology department of tertiary care teaching hospital. Int J Basic Clin Pharmacol. 2017; 6:53-60.

4. American Diabetes Association. Standards of medical care in diabetes-2019. Diagnosis and classification of Diabetes mellitus. Diabetes Care. 2019; 42:S13-29. PMid: 30559228. https://doi.org/10.2337/dc19-S002

5. Raphael M, Vijayanarayana K, Thunga G, Rao NK, Sreedharan N. Utilization pattern of anti-diabetic drugs in Type-2 Diabetes Mellitus in Tertiary Care Hospital. Res J Pharm Technol. 2017; 10:2063-8. https://doi. org/10.5958/0974-360X.2017.00360.2

6. Anilasree BP, Sreekumar S, Nazeer N, Husna P. Drug utilization evaluation of anti diabetic therapy with Type-2 Diabetes Mellitus of a tertiary care hospital in Calicut. J Med Pharm Allied Sci. 2019; 8:2235-53. https://doi. org/10.22270/jmpas.v8i3.841

7. Shrestha JT, Shrestha H, Prajapati M, Karkee A, Maharjan A. Adverse effects of oral hypoglycemic agents and adherence to them among patients with Type-2 Diabetes Mellitus in Nepal. JLMC. 2017; 5:34-40. https://doi.org/10.22502/ jlmc.v5i1.126

8. Agarwal AA, Jadhav PR, Deshmukh YA. Prescribing pattern and efficacy of anti-diabetic drugs in maintaining optimal glycemic levels in diabetic patients. J Basic Clin Pharm. 2014; 5:79-83. PMid: 25278671 PMCid: PMC4160724. https://doi.org/10.4103/0976-0105.139731

9. Chu WM, Ho HE, Huang KH, Tsan YT, Liou YS, Wang YH et al. The prescribing trend of oral antidiabetic agents for Type-2 diabetes in Taiwan. Medicine. 2017; 96(43):e8257.
PMid: 29068991 PMCid: PMC5671824. https://doi. org/10.1097/MD.0000000000008257

10. Bhavana P, Kumar VS, Divya N, Pratheek KP, Rao GE. Assessment of the prescription pattern of oral hypoglycemic drugs in uncomplicated Diabetic Mellitus patients at tertiary care hospital. IJPSR. 2018; 9(8):3487-92.

11. Pankaj CK, Satendra SP, Dhananjay P, Kumud R, Rajmangal C, Bhanu P. A prospective study on drug utilization pattern of anti-diabetic drugs in a tertiary care teaching hospital of eastern Uttar Pradesh, India. Int J Res Med Sci. 2019; 7:669. https://doi.org/10.18203/2320-6012.ijrms20190915

12. Sharma T, Sahai R, Bala S, Dhasmana DC, Kaeley N. Prescribing pattern of oral anti-diabetic agents in Type-2 Diabetes Mellitus patients in a tertiary care hospital. Int J Basic Clin Pharmacol. 2018; 7:956. https://doi. org/10.18203/2319-2003.ijbcp20181642

13. Mani G, Neelam R. Investigation of outpatient prescribing pattern of antidiabetic drugs in Type - 2 diabetic patients - a study conducted at a tertiary care hospital. IOSR J Phar Bio Sci. 2015; 10:26-30.

14. Karthikeyan V, Maadhusudhan S, Selvamuthukumran S. Studies on prescribing pattern in the management of Diabetes Mellitus in rural teaching hospital. Saudi J Med Pharm Sci. 2016; 2:100-7.

15. Mahmood M, Reddy RC, Lahari JR S, Fatima S, Shinde P, Reddy $S$ A et al. Prescription pattern analysis of antidiabetic drugs in Diabetes Mellitus and associated comorbidities. Clin Inves (Lond). 2017; 8:5-12. https://doi.org/10.4172/ Clinical-Investigation.1000123

16. Sasisekhar TV, Shabana S, Bhargav SY. Gender: Does it have role has role in glycemic control and diabetes distress in Type-2 diabetes. IOSR-JDMS. 2013; 4: 48-51. https://doi. org/10.9790/0853-0464851

17. Ashutosh K, Ipseeta RM, Sandeep R. Assessment of prescription pattern of antidiabetic drugs in the outpatient department of a tertiary care hospital. Int J Clin Endocrinal Metab. 2017; 3:1-7. https://doi.org/10.17352/ijcem.000021

18. Muthukumar A, Sridevi M, Gayathri R, Sundar MS, Ganapathy A, Mohan RS. Pharmacovigilance study of antidiabetic drugs in hypertensive patients in a territory hospital in Coimbatore zone. Scholars Research Library Der Pharmacia Lettre. 2017; 9:70-6.

19. Alex SM, Sreelekshmi BS, Smitha S, Jiji KN, Menon AS, Uma Devi P. Drug utilization pattern of anti-diabetic drugs among diabetic outpatients in a tertiary care hospital. Asian J Pharm Clin Res. 2015; 8:144-6.

20. Dominic A, Joseph J, Augustin RM, Begum R, Nanjwade $\mathrm{BK}$, et al. Study of drug use evaluation on oral antihyperglycemic agents in Type-2 Diabetes Mellitus and their potential drug-drug interactions. Int J Clin Endocrinal Metab. 2016; 5:1884-96. 